\title{
MECHANICAL AND BIOCHEMICAL PROPERTIES OF HUMAN ARTICULAR CARTILAGE IN OSTEOARTHRITIC FEMORAL HEADS AND IN AUTOPSY SPECIMENS
}

\author{
S. ROBERTS, B. WEIGHTMAN, J. URBAN, D. CHAPPELL
}

\author{
From Charles Salt Research Centre, Robert Jones \& Agnes Hunt Orthopaedic Centre, Oswestry
}

\begin{abstract}
We studied the mechanical and biochemical properties of articular cartilage from 22 osteoarthritic femoral heads obtained at operation and 97 femoral heads obtained at autopsy. Cartilage from the zenith and from the antero-inferior aspect of each head was tested both in tension and in compression. Water content, swelling ability and proteoglycan content were measured, the cartilage was examined histologically and the density of the underlying bone was assessed.

Fifty-five of the autopsy specimens were defined as macroscopically normal because they exhibited no progressive fibrillation patterns on staining with Indian ink; but significant changes in water content, bone density and tensile strength related to age were seen in this group. In 20 pairs of femoral heads which were both macroscopically normal, we found, surprisingly, that cartilage from the left and right sides of the same patient was sometimes very different.

Compared with the normal autopsy specimens the osteoarthritic specimens had a significantly increased swelling ability, a lower proteoglycan content and impaired mechanical properties, being both weaker in tension and softer in compression. Abnormal autopsy specimens had values intermediate between those of osteoarthritic and normal groups. Results from this abnormal group suggest that there is no primary loss of proteoglycan in early osteoarthritis.
\end{abstract}

The properties of the remaining articular cartilage in severe osteoarthritis are now fairly well accepted. Compared with the normal tissue there is a loss of proteoglycans (Byers et al. 1977; Venn and Maroudas 1977) as well as a change in their structure; they are less aggregated, more extractable and have an increased ratio of chondroitin sulphate to keratan sulphate (McDevitt and Muir 1976; Sweet et al. 1977; Vasan 1980). The tissue is reported to have an increased water content (McDevitt and Muir 1976; Byers et al. 1977), and has been shown to be softer in compression (Kempson, Freeman and Swanson 1971) and weaker in tension (Kempson et al. 1973; Wirth et al. 1980). However, the sequence in which these changes occur and hence the pathway of degeneration is less clear. The initial event in the pathway could be biochemical or mechanical and might result first in a

S. Roberts, PhD. Biochemist

Charles Salt Research Centre, Robert Jones \& Agnes Hunt Orthopaedic Hospital, Oswestry, Salop SY 107 AG, England.

B. Weightman. PhD. Lecturer

D. Chappell, MSc, Research Officer

Biomechanics Unit. Department of Mechanical Engineering, Imperia College, London SW7 2BX. England.

J. Urban, PhD. Research Assistant

Department of Medical Engineering, Parks Road, Oxford OX13PJ, England.

Requests for reprints should be sent to Dr S. Roberts.

( 1986 British Editorial Society of Bone and Joint Surgery $0301-620 \times / 86 / 2031 \$ 2.00$ depletion of proteoglycan from the matrix, or in a breakdown of the collagen framework allowing increased hydration and then release of proteoglycans.

Loss of proteoglycan could be brought about by an increase in degradative enzyme activity which in turn might affect collagen fibril formation (Ali and Bayliss 1974). Some attempt at repair might initially be made by the chondrocytes, with increased cellular activity and proteoglycan synthesis (Mankin, Johnson and Lippiello 1981). Mankin et al. believe that with advancing disease collagen is affected similarly but to a lesser degree. Eventually the degradative process is greater than the repair process, resulting in the end-stage disease and total loss of cartilage (Mankin 1980).

Other workers (Maroudas 1976; Weightman and Kempson 1979; Freeman 1980) suggest that fatigue and breakdown of the collagen meshwork may be the earliest event and that the increased water content which occurs in early osteoarthritis supports this hypothesis. An increase in hydration is one of the first changes in the dog model of osteoarthritis (McDevitt and Muir 1976).

The present work aimed to study the sequence of changes which occur in early osteoarthritis, and in particular to test the hypothesis that a breakdown of the collagen meshwork is the initiating event. If this were so, particularly if this occurred in the mid or deep zones, one might expect an increase in hydration before macro- 
scopic surface fibrillation became obvious. The tissue might be thicker and its tensile strength would be lower.

It is possible to monitor the disease from the beginning in animal models but for obvious reasons it is not easy to obtain human cartilage in an early stage of osteoarthritis. It was therefore decided to study random samples of cadaveric femoral heads. Since the incidence of osteoarthritis is approximately $4 \%$ to $5 \%$ (Byers, Contepomi and Farkas 1970; Jørring 1980), it was hoped that a sample of 100 femoral heads would provide one or more specimens at each of the appropriate stages of the disease. Because the numbers of both samples and tests were large, the tests had to be basic. Measurements were therefore made of thickness, water content and swelling ability, proteoglycan content, and the tensile and compressive properties of the cartilage. The histology of the cartilage as well as the density of the underlying bone were also examined.

All tests were carried out at two standard locations on the femoral heads, one at the zenith, the other midway between the anterior and inferior poles. These sites were chosen because they were the areas of maximum and minimum degeneration in a pilot study of osteoarthritic femoral heads. For the purpose of obtaining "normal" values each specimen was classified according to the location of any surface fibrillation found on staining with Indian ink (Meachim 1972). No specimens were completely free of fibrillation, but those which showed only non-progressive fibrillation (Byers 1974) were classified as normal; all others were included in the abnormal group.

Besides providing a baseline with which to compare abnormal specimens, results from the normal group provided an opportunity to study the changes in mechanical and biochemical properties of articular cartilage that might occur with age. Also, because the majority of specimens were collected in bilateral pairs (only five were not), an opportunity was provided to study the relationship between properties in a pair of joints. There is a common belief that patients who have osteoarthritis of one of a pair of joints have an increased likelihood of developing the disease in the opposite joint, suggesting a relationship between the properties of the tissues. This theory was tested on 20 pairs of femoral heads in which specimens from both left and right hips were both macroscopically normal.

\section{MATERIALS AND METHODS}

Ninety-seven femoral heads were obtained at autopsy from subjects aged between 6 and 90 years (mean $63.1 \pm$ 19 years). Fifty were from the right side and 47 from the left. Approximately 300 femoral heads were obtained at hip arthroplasty operations for osteoarthritis; of these only 22 had sufficient cartilage remaining. Those tested ranged in age from 50 to 77 years (mean 62.4 \pm 7.6 ). Specimens were stored at $-20 \mathrm{C}$ in sealed plastic bags until they were tested, the specimens were then thawed in
Ringer's solution at $4 \mathrm{C}$ for two hours and the degree of surface fibrillation was assessed with Indian ink (Meachim 1972). Cores of cartilage, $10 \mathrm{~mm}$ in diameter, were removed from the zenith and the antero-inferior sites, with 10 to $20 \mathrm{~mm}$ of underlying bone attached. The thickness of the cartilage was measured at a standard point on each plug using a micrometer depth gauge under a dissecting microscope.

Bone density. Microfocal radiographs were taken of the cores, and the density of the bone at a depth of $4 \mathrm{~mm}$ below the surface was measured by digitising and analysing the image from a television camera (Koyo CCTV) on a Nova 3 minicomputer (Data General), which was part of a Scintag-Berthold Digicamera (Park et al. 1984). The bone was then trimmed off on a freezing microtome to leave a disc of cartilage.

Compressive modulus. The disc of cartilage was compressed using a variation of the indentation apparatus used by Kempson et al. (1971a) to test whole femoral heads. In the present study a two-second creep modulus $(E)$ was calculated using the following equation:

$$
E=\frac{\text { stress }}{\text { strain }}
$$

where

$$
\text { strain }=\frac{\text { compression }(\mathrm{mm}) \operatorname{after} 2 \mathrm{~s}}{\text { original thickness }(\mathrm{mm})}
$$

A plane-ended indentor of diameter $3.2 \mathrm{~mm}$ was used and the cartilage subjected to a stress of $1.4 \mathrm{MN} / \mathrm{m}^{2}$.

Tensile properties. The tensile stiffness and strength of two $200 \mu \mathrm{m}$-thick slices were measured for each site. The first slice was the most superficial and the second was the third slice down from the surface. All specimens were taken adjacent to the sites of the cores and parallel to the pin-prick pattern determined by the technique of Hultkrantz (1898). Dumb-bell shaped specimens of cartilage were tested in an Instron materials testing machine (Model 1122) with the cross-head set to move at $5 \mathrm{~mm} / \mathrm{min}$. Gauge marks of black cotton, attached approximately $4 \mathrm{~mm}$ apart, were used to measure extension of the specimens, using a video camera (Elton EC 1702) and an automatic tracking system (Hampton Video Systems, SP123 Image Analyser). The ultimate tensile strength (UTS) was calculated as being equal to

$$
\frac{\text { the maximum force to cause fracture }}{\text { the original cross-sectional area }}
$$

and the tensile stiffness $E_{10}$ was measured as the slope of the stress-strain curve at $10 \%$ strain.

Water content. Water content and swelling ability, for the whole core and also as a profile with depth, were measured on the discs of cartilage after compression testing. The discs were cut into slices approximately $200 \mu \mathrm{m}$ thick, on a freezing microtome, and each slice was weighed, soaked in Ringer's solution for 60 minutes at 4 C. blotted gently, reweighed and dried to a constant weight at $60 \mathrm{C}$. Swelling ability was calculated as a per- 
centage increase of the original wet weight. Since the water content was not measured immediately upon receiving the specimen, attempts were made to assess the effect of storage and the test methods on the value of the water content; it appeared to be negligible (Roberts 1984).

Proteoglycan content. Proteoglycan content was assessed by measuring the fixed charge density (FCD; Maroudas and Thomas 1970) of the dried slices.

Histology. Histological examination was made of cartilage adjacent to the sampling sites of selected specimens. Frozen sections were stained with haematoxylin and eosin. They were also stained with alcian blue using the critical electrolyte concentration method of Scott and Dorling (1965): in this test, the alcian blue stains with increasing selectivity as increasing amounts of magnesium chloride are incorporated into the dye solution, and hence staining with $0.4 \mathrm{M}$-magnesium chloride could be due to both keratan and chondroitin sulphate, whereas with $0.9 \mathrm{M}$ only to keratan sulphate. The presence of collagen Types I, II, III, proteoglycan and fibronectin was tested for by immunofluorescent staining with the appropriate antisera (Roberts 1984).

Data processing was carried out on a Digital Equipment PDP11/44 computer running the Massachusetts General Hospital Utility Multiprogramming Medinfo package. Significance was tested using Student's $t$-test for small samples in which the population variances were not assumed to be equal (Parker 1979). All parameters were plotted against age, on a main-frame computer
(CDC Cyber 174, graphics communication system via CDC 1700). A straight line was fitted for the normal values by the method of least mean squares.

\section{RESULTS}

To classify the autopsy specimens two independent assessments were made. Fifty-five of the 97 femoral heads had only non-progressive fibrillation patterns (Byers 1974) and were classified as normal. The mean age was $61.7 \pm 18.6$ years. Of the remaining 42 (mean age $64.9 \pm 20.4$ years), which were termed abnormal, two were typical of femoral heads of patients with clinical osteoarthritis, with cartilage erosion and bone exposure. Ten others were considered to show early osteoarthritis with fibrillation at the zenith, in some cases severe. The remaining 30 specimens were difficult to classify: some were clearly abnormal while for others the two assessments differed. The two specimens obtained from a sixyear-old were included in the abnormal group since, not being skeletally mature, they would not belong with the normal adult group. In the osteoarthritic specimens removed at operation, most of the remaining cartilage was fibrillated.

Mean values of test parameters for the three groups of specimens are summarised in Table I, together with the level of significance of differences from the normal autopsy specimens where this is appropriate.

Thickness. At the zenith the cartilage in the osteoarthritic group was significantly thinner than that of the normal group.

Table I. Comparative values for macroscopically normal and abnormal autopsy specimens and osteoarthritic femoral heads obtained at operation. Significant differences from the normal group are shown where applicable

\begin{tabular}{|c|c|c|c|c|c|c|c|c|c|c|c|c|c|}
\hline \multirow[b]{2}{*}{ Properties } & \multirow[b]{3}{*}{${ }_{\mathrm{Z}}^{\mathrm{AI}}$} & \multicolumn{3}{|c|}{ Normal autopsy specimens } & \multicolumn{5}{|c|}{ Abnormal autopsy specimens } & \multicolumn{4}{|c|}{ Osteoarthritic specimens } \\
\hline & & Mean & \pm s.d. & $n$ & Mean & \pm & s.d. & $n$ & $\boldsymbol{P}$ & Mean & \pm s.d. & $n$ & $\boldsymbol{P}$ \\
\hline Thickness $(\mathrm{mm})$ & & $\begin{array}{l}1.57 \\
2.04\end{array}$ & $\begin{array}{l} \pm 0.33 \\
\pm 0.36\end{array}$ & $\begin{array}{l}54 \\
54\end{array}$ & $\begin{array}{l}1.75 \\
2.05\end{array}$ & $\begin{array}{l} \pm \\
\pm\end{array}$ & $\begin{array}{l}0.49 \\
0.51\end{array}$ & $\begin{array}{l}38 \\
37\end{array}$ & & $\begin{array}{l}1.62 \\
1.22\end{array}$ & $\begin{array}{l} \pm 0.67 \\
\pm 0.57\end{array}$ & $\begin{array}{r}21 \\
7\end{array}$ & $<0.01$ \\
\hline Bone density & $\begin{array}{l}\text { Al } \\
\mathrm{Z}\end{array}$ & $\begin{array}{l}1704 \\
2388\end{array}$ & $\begin{array}{l} \pm 760 \\
\pm 903\end{array}$ & $\begin{array}{l}55 \\
55\end{array}$ & $\begin{array}{l}2143 \\
2669\end{array}$ & $\begin{array}{l} \pm \\
\pm\end{array}$ & $\begin{array}{l}807 \\
890\end{array}$ & $\begin{array}{l}38 \\
39\end{array}$ & $<0.02$ & $\begin{array}{l}1874 \\
2699\end{array}$ & $\begin{array}{l} \pm 1022 \\
\pm 1159\end{array}$ & $\begin{array}{r}20 \\
7\end{array}$ & \\
\hline 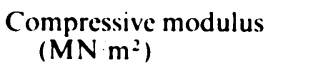 & $\begin{array}{l}\mathrm{AI} \\
\mathrm{Z}\end{array}$ & $\begin{array}{r}9.7 \\
13.1\end{array}$ & $\begin{array}{l} \pm 3.6 \\
\pm 3.6\end{array}$ & $\begin{array}{l}53 \\
55\end{array}$ & $\begin{array}{r}9.8 \\
11.0\end{array}$ & $\begin{array}{l} \pm \\
\pm\end{array}$ & $\begin{array}{l}5.1 \\
4.5\end{array}$ & $\begin{array}{l}37 \\
36\end{array}$ & $<0.025$ & $\begin{array}{l}5.4 \\
6.2\end{array}$ & $\begin{array}{l} \pm 4.0 \\
\pm 2.1\end{array}$ & $\begin{array}{r}13 \\
5\end{array}$ & $\begin{array}{l}<0.001 \\
<0.001\end{array}$ \\
\hline $\begin{array}{r}\text { UTS }\left(\mathrm{MN} \mathrm{m}^{2}\right) \text { Slice } 1 \\
\text { Slice } 3\end{array}$ & $\begin{array}{l}\mathrm{AI} \\
\mathrm{Z} \\
\mathrm{AI} \\
\mathrm{Z}\end{array}$ & $\begin{array}{r}10.6 \\
13.6 \\
7.8 \\
8.5\end{array}$ & $\begin{array}{l} \pm 4.2 \\
\pm 5.4 \\
\pm 5.8 \\
\pm 5.1\end{array}$ & $\begin{array}{l}42 \\
48 \\
31 \\
42\end{array}$ & $\begin{array}{r}12.0 \\
12.4 \\
10.1 \\
6.2\end{array}$ & $\begin{array}{l} \pm \\
\pm \\
\pm \\
\pm\end{array}$ & $\begin{array}{l}4.9 \\
5.3 \\
6.9 \\
4.8\end{array}$ & $\begin{array}{l}19 \\
28 \\
16 \\
24\end{array}$ & & $\begin{array}{l}5.1 \\
8.2 \\
3.9 \\
3.1\end{array}$ & $\begin{array}{ll} \pm & 1.4 \\
\pm & 3.6 \\
\pm & 0.6 \\
\pm & 1.1\end{array}$ & $\begin{array}{l}3 \\
4 \\
2 \\
3\end{array}$ & $\begin{array}{l}<0.005 \\
<0.05 \\
<0.005 \\
<0.001\end{array}$ \\
\hline $\begin{array}{r}E_{10}\left(\mathrm{MN} \mathrm{m}^{2}\right) \text { Slice } 1 \\
\text { Slice } 3\end{array}$ & $\begin{array}{l}\mathrm{AI} \\
\mathrm{Z} \\
\mathrm{AI} \\
\mathrm{Z}\end{array}$ & $\begin{array}{r}58.8 \\
100.0 \\
18.5 \\
26.8\end{array}$ & $\begin{array}{l} \pm 30.8 \\
\pm 49.7 \\
\pm 12.1 \\
\pm 19.9\end{array}$ & $\begin{array}{l}42 \\
49 \\
30 \\
45\end{array}$ & $\begin{array}{l}60.5 \\
85.8 \\
22.0 \\
21.1\end{array}$ & $\begin{array}{l} \pm 4 \\
\pm 4 \\
\pm \\
\pm 1\end{array}$ & $\begin{array}{r}42.0 \\
41.2 \\
9.2 \\
11.4\end{array}$ & $\begin{array}{l}21 \\
29 \\
16 \\
23\end{array}$ & & $\begin{array}{r}26.3 \\
48.2 \\
11.0 \\
3.4\end{array}$ & $\begin{array}{l} \pm 12.3 \\
\pm 45.5 \\
\pm 1.4 \\
\pm 0.9\end{array}$ & $\begin{array}{l}3 \\
4 \\
2 \\
2\end{array}$ & $\begin{array}{l}<0.025 \\
<0.01 \\
<0.001\end{array}$ \\
\hline Water $(\%)$ & $\begin{array}{l}\text { Al } \\
\mathrm{Z}\end{array}$ & $\begin{array}{l}72.0 \\
69.3\end{array}$ & $\begin{array}{l} \pm 2.2 \\
\pm 2.1\end{array}$ & $\begin{array}{l}53 \\
55\end{array}$ & $\begin{array}{l}72.1 \\
69.4\end{array}$ & $\begin{array}{l} \pm \\
\pm\end{array}$ & $\begin{array}{l}3.7 \\
2.6\end{array}$ & $\begin{array}{l}39 \\
38\end{array}$ & & $\begin{array}{l}72.5 \\
68.6\end{array}$ & $\begin{array}{l} \pm 9.3 \\
\pm 3.9\end{array}$ & $\begin{array}{r}21 \\
7\end{array}$ & \\
\hline Swelling $(\%)$ & $\begin{array}{l}\text { Al } \\
\mathrm{Z}\end{array}$ & $\begin{array}{l}4.75 \\
3.39\end{array}$ & $\begin{array}{l} \pm 2.66 \\
\pm 2.00\end{array}$ & $\begin{array}{l}40 \\
42\end{array}$ & $\begin{array}{l}7.59 \\
5.73\end{array}$ & $\begin{array}{l} \pm \\
\pm\end{array}$ & $\begin{array}{l}6.07 \\
4.88\end{array}$ & $\begin{array}{l}33 \\
31\end{array}$ & $\begin{array}{l}<0.02 \\
<0.02\end{array}$ & $\begin{array}{l}24.7 \\
10.0\end{array}$ & $\begin{array}{l} \pm 41.2 \\
\pm 6.3\end{array}$ & $\begin{array}{r}20 \\
7\end{array}$ & $\begin{array}{l}<0.05 \\
<0.05\end{array}$ \\
\hline FCD wet wt ( $\mathrm{mEq} g)$ & $\begin{array}{l}\text { AI } \\
\text { Z }\end{array}$ & $\begin{array}{l}0.113 \\
0.135\end{array}$ & $\begin{array}{l} \pm 0.026 \\
\pm 0.017\end{array}$ & $\begin{array}{l}50 \\
52\end{array}$ & $\begin{array}{l}0.118 \\
0.131\end{array}$ & $\begin{array}{l}3 \pm \\
\pm\end{array}$ & $\begin{array}{l}0.022 \\
0.018\end{array}$ & $\begin{array}{l}37 \\
38\end{array}$ & & $\begin{array}{l}0.083 \\
0.105\end{array}$ & $\begin{array}{l} \pm 0.024 \\
\pm 0.014\end{array}$ & $\begin{array}{r}20 \\
7\end{array}$ & $\begin{array}{l}<0.001 \\
<0.001\end{array}$ \\
\hline $\begin{array}{l}\text { Al, antero-inferior site } \\
\text { Z, zenith } \\
\text { FCD. fixed charge density }\end{array}$ & $\begin{array}{l}\mathrm{U} \\
\mathrm{E}_{1}\end{array}$ & $\begin{array}{l}\text { ultim } \\
\text { nsile }\end{array}$ & $\begin{array}{l}\text { e tensile } \\
\text { iffness }\end{array}$ & & & & & & & & & & \\
\hline
\end{tabular}


Bone density. The abnormal group had a higher mean value for bone density at the antero-inferior site. The spread of results was slightly larger in the osteoarthritic group. perhaps as a result of both sclerosis and cyst formation during the progression of the disease.

Compressive modulus. Values for the osteoarthritic group were significantly lower than those of the normal specimens at both locations. At the zenith the abnormal autopsy group was on average softer than the normals but not as soft as the osteoarthritic group.

Tensile properties. Both tensile strength and tensile stiffness were greatly reduced in the osteoarthritic group, very significantly in most cases, even though the sample numbers were small. In the autopsy groups at the zenith the abnormals had values lower than the normals, although this was not statistically significant, whilst at the antero-inferior site they were slightly higher.

Water content. There was little or no difference in water content between any of the groups, but swelling ability was significantly increased in both the abnormal and the osteoarthritic groups, particularly the latter. The profiles for water content of the normal and abnormal autopsy groups showed a drop in water content with depth (Fig. 1). This trend was not seen in the osteoarthritic group where the water content remained approximately constant at different depths.

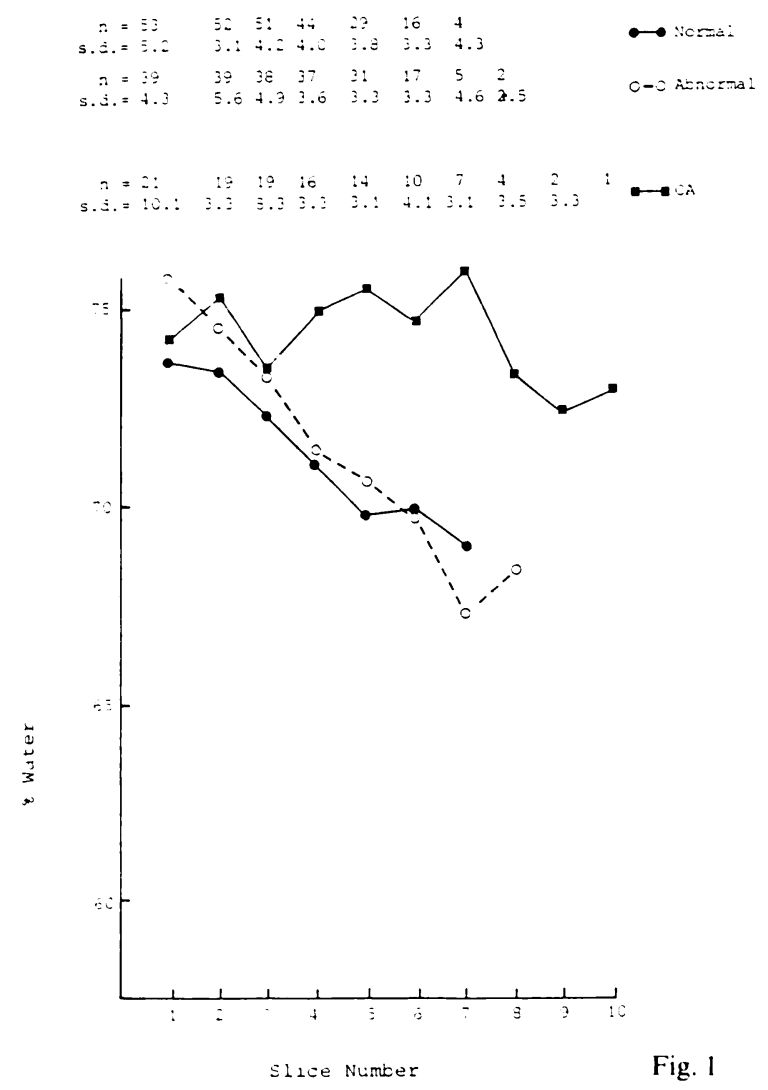

Figure 1-The change in water content with depth at the antero-inferior site for the three sample groups, normal and abnormal autopsy specimens and the osteoarthritic specimens. Figure 2-Fixed charge density (FCD) for proteoglycan: profile with depth at the zenith for the three groups.
Fixed charge density (for proteoglycan content). The average fixed charge density (per wet weight) of the osteoarthritic group was significantly reduced compared to the normal specimens whereas in the abnormal group it was not. The mean fixed charge density of the osteoarthritic group was lower at all depths than that of the normal group. The abnormal autopsy groups followed the normal profile at most depths (Fig. 2).

Histology. Osteoarthritic specimens stained with haematoxylin and eosin showed severe disorganisation, with large clefts at the surface, clusters of cells or in some cases empty lacunae. Uptake of alcian blue was very weak with both $0.4 \mathrm{M}$ and $0.9 \mathrm{M}$-magnesium chloride, showing overall loss of both keratan and chondroitin sulphate (Scott and Dorling 1965). Immunofluorescent staining gave results similar to those seen in normal specimens, with the cartilage matrix staining positively for Type II collagen whilst negatively for Type I. Staining for Type III was positive pericellularly after trypsin treatment. The cells stained very strongly for proteoglycan, with some staining throughout the matrix. Staining for fibronectin was also strong for the cells, though here the distribution tended to be more around the perimeter of the cells than for proteoglycan.

Changes with age. For most parameters the trend was the same at both the zenith and antero-inferior sites (the two

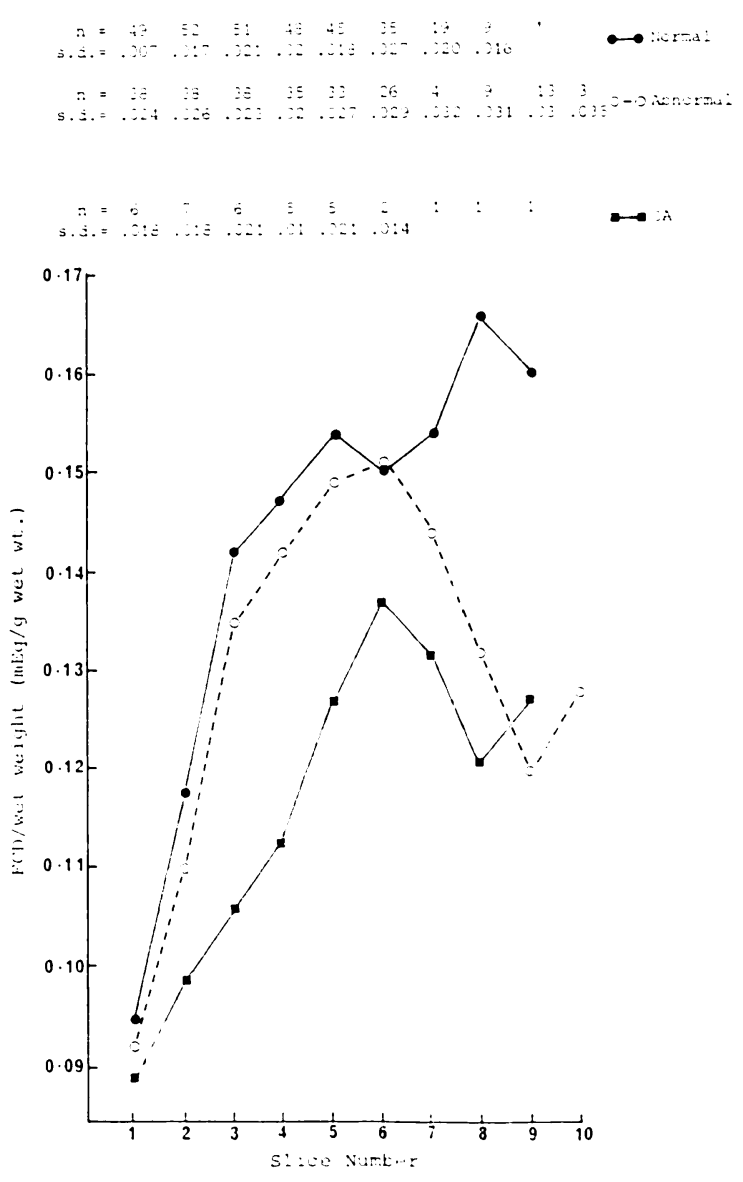

Fig. 2 
Table II. Changes in properties with each year of age

\begin{tabular}{|c|c|c|c|c|c|c|c|c|}
\hline \multirow[b]{2}{*}{ Properties } & \multicolumn{4}{|c|}{ Antero-inferior } & \multicolumn{4}{|l|}{ Zenith } \\
\hline & $r$ & $m$ & $n$ & $\boldsymbol{P}$ & $r$ & $m$ & $n$ & $\boldsymbol{P}$ \\
\hline Thickness & -0.22 & -0.14 & 54 & NS & -0.09 & -0.06 & 54 & NS \\
\hline Bone density & -0.52 & -21.0 & 55 & $<0.001$ & -0.19 & -9.29 & 55 & NS \\
\hline Water content & 0.05 & 0.01 & 53 & NS & -0.39 & -0.04 & 55 & $<0.005$ \\
\hline FCD content & 0.27 & 0.00035 & 50 & NS & 0.12 & 0.00011 & 52 & NS \\
\hline Tensile strength: Slice 1 & -0.37 & -0.08 & 42 & $<0.02$ & -0.37 & -0.11 & 48 & $<0.01$ \\
\hline Slice 3 & -0.60 & -0.19 & 31 & $<0.001$ & -0.75 & -0.21 & 42 & $<0.001$ \\
\hline Tensile stiffness: Slice 1 & 0.14 & 0.22 & 42 & NS & 0.12 & 0.33 & 49 & NS \\
\hline Slice 3 & 0.08 & 0.12 & 29 & NS & -0.12 & -0.13 & 45 & NS \\
\hline Compressive stiffness & -0.18 & -0.03 & 53 & NS & -0.09 & -0.02 & 55 & NS \\
\hline
\end{tabular}

exceptions were for water content and tensile stiffness of the third slice). A summary of results can be seen in Table II.

The density of bone decreased with age, being significant at the antero-inferior site (see Table II). Because a sex difference was suspected for this measurement, osteoporosis being more common in women than men, the data were re-analysed for male and female specimens independently, but the regression and correlation coefficients for the females alone were similar to those for the whole group.

Compressive stiffness did not show a statistically significant change with increasing age at either site. Tensile strength, however, showed a significant decrease with age at both sites, particularly for the third slice (Fig. 3).

At the zenith the total water content decreased significantly with age $(P<0.005 ; r=-0.39$; Fig. 4) whilst at the antero-inferior site there was no significant change.

Histologically no clear changes were seen with age alone, apart from those in a pair of specimens from a sixyear-old child. Here the tissue was very cellular and the cell arrangement was less columnar than that in sections from older specimens. The immunofluorescent staining pattern also differed for this specimen; none of the other specimens stained for Type I collagen, but a narrow strip at the surface in the six-year-old specimen stained positively.

In summary, the statistically significant changes with increasing age were a decrease in tensile strength at both sites, in bone density at the antero-inferior site and in water content at the zenith. There was a tendency for the proteoglycan content and tensile stiffness to increase with age, but this was not statistically significant.

Bilateral specimens. Mean values for the different param-

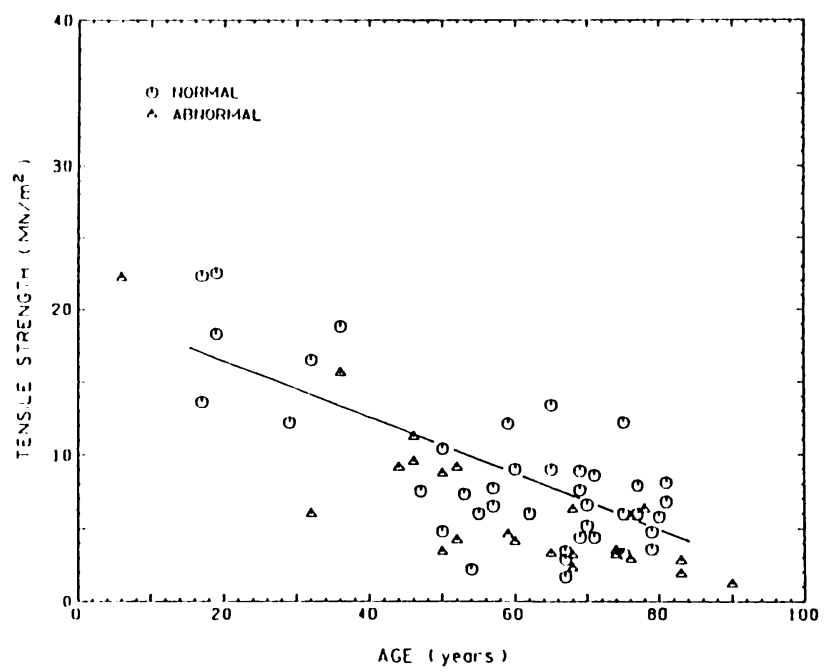

Fig. 3

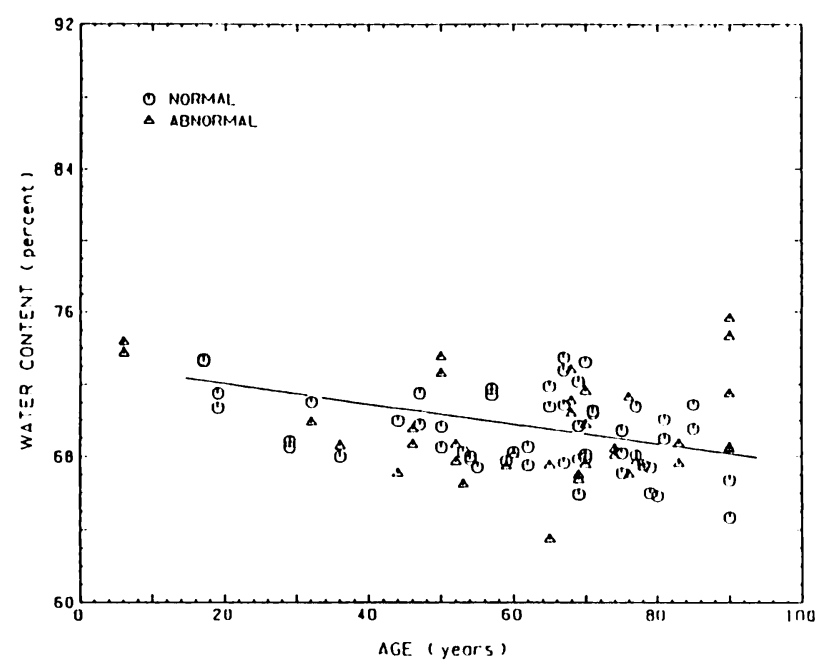

Fig. 4

Figure 3-Change with age in tensile strength of the third slice at the zenith $(y=20.81-0.21 x: r=-0.75)$. Figure $4-$ Change in water content with age at the zenith $(y=72.0-0.04 x ; r=-0.39)$. 
Table III. Correlation $(r)$ and regression $(m)$ coefficients for plots of left versus right hips in normal bilateral pairs

\begin{tabular}{|c|c|c|c|c|c|c|}
\hline \multirow[b]{2}{*}{ Properties } & \multicolumn{3}{|c|}{ Antero-inferior } & \multicolumn{3}{|c|}{ Zenith } \\
\hline & $r$ & $m$ & $\boldsymbol{P}$ & $r$ & $m$ & $\boldsymbol{P}$ \\
\hline Compressive stiffness & 0.53 & 0.47 & $<0.02$ & 0.25 & 0.29 & \\
\hline Tensile strength: Slice 1 & 0.52 & 0.37 & & 0.08 & 0.09 & \\
\hline Slice 3 & 0.59 & 0.40 & & 0.76 & 0.77 & $<0.01$ \\
\hline Tensile stiffness: Slice 1 & -0.23 & -0.19 & & 0.44 & 0.37 & \\
\hline Slice 3 & 0.15 & 0.20 & & 0.07 & 0.06 & \\
\hline Water content & 0.19 & 0.14 & & 0.75 & 0.74 & $<0.001$ \\
\hline$\%$ increase in weight & 0.25 & 0.32 & & 0.22 & 0.53 & \\
\hline FCD/wet weight & 0.20 & 0.208 & & 0.22 & 0.253 & \\
\hline
\end{tabular}

Table IV. Significant relationships between properties of articular cartilage

\begin{tabular}{|c|c|c|c|c|c|}
\hline \multirow[b]{2}{*}{ Pairs of properties } & & \multicolumn{2}{|c|}{ Antero-inferior } & \multicolumn{2}{|l|}{ Zenith } \\
\hline & & $r$ & $\boldsymbol{P}$ & $r$ & $\boldsymbol{P}$ \\
\hline Water content & UTS Slice 3 & & & 0.39 & $<0.02$ \\
\hline FCD/wet wt & UTS Slice 3 & -0.59 & $<0.001$ & -0.46 & $<0.01$ \\
\hline Water content & Compressive stiffness & -0.54 & $<0.001$ & & \\
\hline Thickness & Water content & & & 0.37 & $<0.01$ \\
\hline Thickness & UTS Slice 3 & & & -0.33 & $<0.05$ \\
\hline $\mathrm{E}_{10}$ Slice 1 & $\mathrm{E}_{10}$ Slice 3 & 0.47 & $<0.01$ & 0.47 & $<0.005$ \\
\hline Compressive stiffness & UTS Slice 1 & 0.58 & $<0.001$ & & \\
\hline Compressive stiffness & $\mathrm{E}_{10}$ Slice 1 & 0.37 & $<0.02$ & 0.53 &.$<0.001$ \\
\hline
\end{tabular}

eters were calculated and compared for specimens from the left and right hips. No significant differences were found between the two sides. Of the bilaterally collected specimens there were 20 pairs in which both hips of the pair were classified as normal. The values of these 20 were plotted left versus right. As can be seen from the correlation and regression coefficients in Table III the values for left and right femoral heads of corresponding pairs were very different.

Correlation between different parameters. Since a large number of parameters were measured on a fairly large sample number, an opportunity was provided to study possible relationships. Any two parameters suspected of being related were plotted against each other. The correlation and regression coefficients of statistically significant linear relationships can be seen in Table IV.

There was a positive correlation between compressive and tensile properties with an increase in compressive stiffness coinciding with an increase in tensile properties (Fig. 5). Thus if cartilage was weak in tension it tended to be soft in compression. There was a correla-

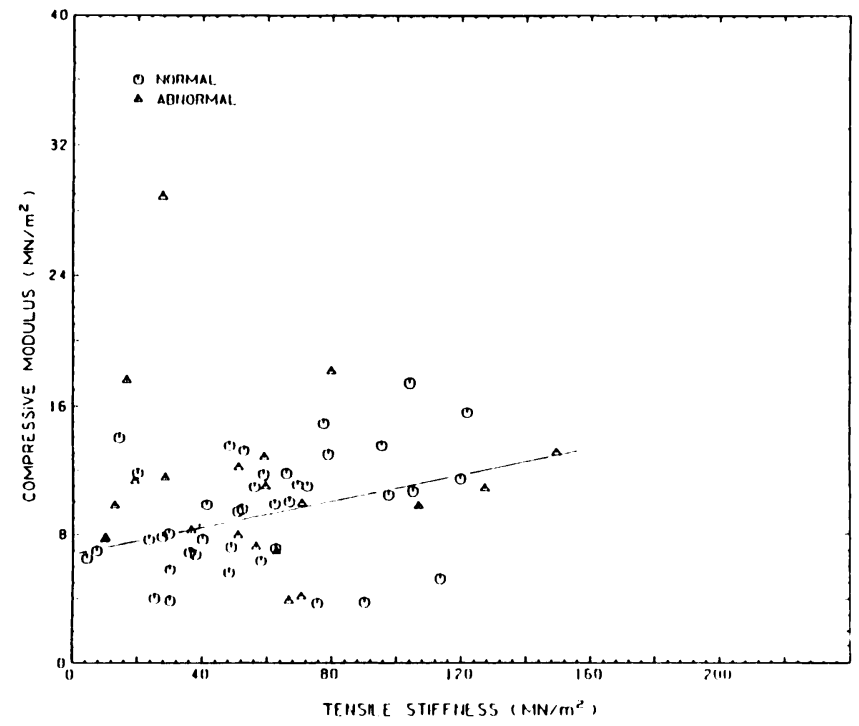

Fig. 5

The relationship between the compressive modulus and the tensile stiffness of the superficial slice in specimens taken from the antero-inferior site $(y=6.94+0.04 x ; r=0.37)$. 
tion between tensile properties of the first and third slices, as might be expected.

Compressive stiffness was also related to water content, with the softer tissue having a higher water content (Fig. 6). One of the most interesting results was the lack of correlation between compressive stiffness and proteoglycan content, as measured by fixed charge density (Fig. 7).

\section{DISCUSSION}

Changes with age. There is no doubt that articular cartilage changes with age. For example, there is an increased incidence of so-called non-progressive fibrillation (Meachim and Emery 1973) together with a change in the

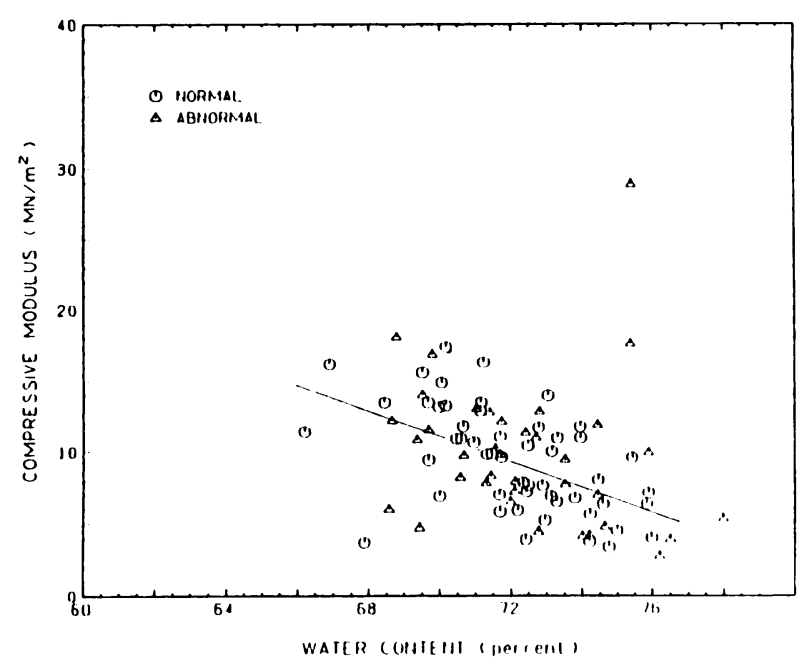

Fig. 6

The relationship between compressive modulus and water content in cartilage from the antero-inferior site $(y=74.02-0.90 x$; $r=-0.54)$.

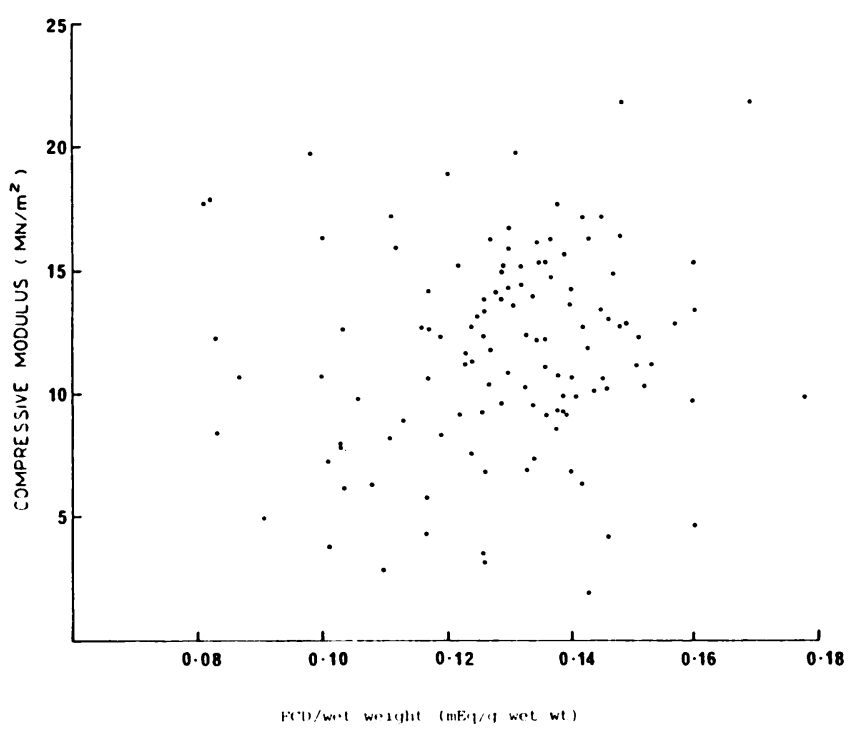

Fig. 7

A plot of compressive modulus against fixed charge density for all specimens tested at the zenith $(y=8.94+21.70 x: r=0.10)$. chemical make-up of the tissue. There is a shift in the ratio of the keratan to chondroitin sulphate (Hjertquist and Lemperg 1972), a decrease in the molecular weight of proteoglycan in the tissue (Garg and Swann 1981) and a decrease in water content (Venn 1978). Certain mechanical properties also change with age. The tensile strength of cartilage from the knee, for example, has been shown to decrease from the third decade onwards (Kempson 1982).

Despite the fact that in the present study several specimens in excellent condition were obtained from patients in the eighth and ninth decade, we also found that some properties of cartilage change with age. The fact that the two tensile properties we tested show different trends with age is interesting. The significant decrease in ultimate tensile strength, particularly at the zenith, is in agreement with the findings of Kempson (1982) for cartilage from the human knee. In the superficial zone he found a slight increase in strength up to the third decade after which there was a fall, whereas in the deep zone there was a continual decrease from the first decade onwards. Roth and Mow (1980) found a similar difference in bovine cartilage. tensile strength falling with increasing age in the mid and deep zones but not in the surface zone. Our results agree with this but we found a higher degree of correlation and regression for the third slice than for the first slice (Table II), which therefore appears to be less affected by age.

Tensile stiffness, however, showed no significant correlation with age, although for all specimens except the third slice at the zenith, the trend was to increase with increasing age (Table II). Kempson (1982) found a decrease in stiffness with age for the superficial zone in the human knee joint after the third decade, but his method of calculation differed from that used in our study. He measured the stiffness at two fixed stresses, 5 and $10 \mathrm{MN} / \mathrm{m}^{2}$ while we measured at $10 \%$ strain. He did not report any results for mid or deep zones.

Tensile stiffness and strength may well reflect different properties of the collagen meshwork. For example, the size and number of individual fibrils might relate to the strength. Venn (1978) found a decrease in collagen per dry weight with age, although this may have represented an increase in mineral or non-collagenous protein. Tensile stiffness might reflect interactions between collagen and the non-collagenous matrix. The degree of binding between macromolecules could be expected to have a bearing on how fast the network can rearrange itself when subjected to stress.

Age changes in collagen cross-linking in cartilage have been reported. For example, an age-dependent decrease in solubility of the collagen molecule in tracheal cartilage (Schnider and Kohn 1982) and human articular cartilage (Chaminade et al. 1982) have been found and attributed to an alteration in the cross-links. Radin et al. (1982) treated bovine cartilage with glutaraldehyde and found that the cartilage became more resistant to 
mechanical wear, possibly because of fixation of the collagen cross-links. Perhaps the amount of cross-linking is inversely related to tensile strength, so that increased cross-linking renders cartilage more brittle and weaker. A more plausible explanation would seem to be the change in the type of cross-links known to occur with increasing age, shown as a decrease in the so-called nonreducible hydroxypyridinium cross-links in human articular cartilage after maturity (Eyre 1982). These changes may be directly responsible for the fall in tensile strength.

Although the density of underlying bone did decrease with age it was surprising that the correlation was only significant at the antero-inferior site; perhaps the trabecular pattern is more variable at the zenith than elsewhere in the femoral head. The finding that the decrease with age for females is parallel to that for males, with only the absolute values differing, is in agreement with other workers (Trotter, Broman and Peterson 1960).

Interpretation of the histology of the specimens is more difficult since it was almost totally subjective. Hence, only outstanding specimens are noticed and subtle trends are likely to be overlooked. Cartilage obtained from the six-year-old child was one such specimen, having an obviously greater cell density and at least some Type I collagen present in the surface layer of the cartilage. Both of these observations agree with findings of other workers. Lothe, Spycher and Rüttner (1979), for example, found a decrease in cell density from 6 to 25 years after which it remained constant. Duance (personal communication) has found Type I collagen in the superficial layer of porcine articular cartilage, but his positive material was also from young, immature animals, mostly about six months old.

Variation between sites. Our results show that cartilage at the zenith is quite different to cartilage at the anteroinferior site. At the zenith the cartilage was significantly thicker, stiffer in compression and stronger in tension at both depths than at the antero-inferior site. In addition, the tissue at the zenith had a significantly lower water content and swelling ability and a higher fixed charge density per wet weight (not significantly per dry weight; Roberts 1984) than at the antero-inferior site. The density of the bone was also significantly greater at the zenith than at the antero-inferior site. These differences could be attributed to the loading pattern within the femoral head. The zenith takes a greater load for a larger proportion of time (Pauwels 1976). According to Wolff's law it is to be expected that the underlying bone would be more dense at this site of increased load. The cartilage too may respond directly to the greater loading here, or perhaps there is an indirect effect via the increased density of the underlying bone. Whatever the cause, there is a real difference between the two locations which emphasises the importance of standardising sampling sites.

Bilateral "normal" specimens. The general lack of agreement between properties of bilateral "normal" pairs of hips was surprising. The finding that there is no significant difference in the mean values of properties of left and right sides is, however, in agreement with earlier workers (Byers et al. 1970) who were looking at anatomical and radiographic properties. If it is true that patients with osteoarthritis of one joint are more likely to develop osteoarthritis in the opposite joint it seems unlikely that this is due to general predisposition, which would affect both sides alike, but rather because of the altered loading caused by attempts to reduce pain from the affected hip.

Relationship between compressive stiffness and proteoglycan content. Another unexpected finding was the lack of correlation between the compressive stiffness (as measured by the two-second creep modulus) and proteoglycan content (as measured by the fixed charge density). Kempson et al. (1970) found a strong relationship between the two parameters, but the discrepancy with our results might be explained by differences in technique. Kempson et al. (1970) measured indentation on the whole femoral head using a hemispherical indentor whereas we used a plane-ended indentor on an isolated disc of cartilage. Isolated plugs may deform by bulging as well as by water flow. Bulging may be related to the collagen network and to tensile properties; creep through water flow is probably more related to the glycosaminoglycan content. When creep is measured on intact femoral heads there can be little bulging deformation and Kempson's results could be expected to be more related to glycosaminoglycan content. However, previous work at Imperial College on whole heads, using fixed charge density measurements, found a similar lack of correlation (Weightman, unpublished results). The stresses and the methods of assessment of proteoglycan were also different in the two studies. Kempson may have tested some slightly fibrillated tissue, since an Indian ink test was not used; this may have weighted his results.

Our study suggests that caution should be exercised on the relationship between particular mechanical properties and biochemical constituents. It seems that compressive properties do not depend on proteoglycan content alone, but probably reflect a combination of all the major constituents and the manner in which they interact.

Changes found in osteoarthritic cartilage. In general the changes in properties of cartilage we found in osteoarthritic specimens agree with those reported by other workers, for example, the location and degree of fibrillation (Byers 1974), and the inevitable reduction in thickness, the reduction in compressive stiffness (Kempson et al. 1971b) and tensile properties (Kempson et al. 1973). A decrease in proteoglycan content has been found previously (Byers et al. 1977: Venn and Maroudas 1977) together with an increase in swelling ability (Maroudas 1976; Maroudas and Venn 1977). The finding that osteoarthritic cartilage had a similar total water content to normal cartilage, however, is in contrast to most previous results. For example. Bollet and Nance (1966) and 
Mankin and Thrasher (1975) found the water content to be raised in human osteoarthritic cartilage in the knee and femoral head respectively. In the dog model of osteoarthritis, McDevitt and Muir (1976) found that an increase in water content was one of the first changes in the development of the disease. This contrast in results may be due to differences in samples; all our osteoarthritic material was severely fibrillated whereas in some other studies this was not the case (Maroudas and Venn 1977).

Osteoarthritic specimens differed from normals at both sites we tested. This implies that osteoarthritis is not a focal disease; changes are seen not only at the site of the primary lesion, usually the zenith, but also throughout the femoral head. Indeed, the initial damage may not be at the zenith; there may be an overall change in the cartilage, but the higher load at the zenith leads to more rapid degeneration.

Since the abnormal autopsy group contained some specimens with severe fibrillation. like that in the early stages of osteoarthritis, it is not surprising that many results for this group fell between those for the normal and the osteoarthritic groups, although few differed significantly from normal.

Progressive changes in autopsy cartilage. If the primary lesion in osteoarthritis is disruption of the collagen meshwork then, since the tensile properties appear to reflect the integrity of that meshwork (Bader et al. 1981), one would expect to find a decrease in tensile strength or stiffness or both as one of the earliest changes. Such cartilage should have an increased ability to swell, as the collagen fibres would fail to restrain the imbibition of water by the hydrophilic proteoglycans to the same degree. With increased uptake of water, the total water content and the thickness could be expected to increase, whilst the compressive modulus might decrease since it would be easier to squeeze water out of the tissue. Finally, proteoglycans could be expected to be lost from the tissue since the collagen fibres would restrain them less well; this could lead to further softening of the tissue, a decrease in thickness and increased stress on adjacent tissue, which might in turn cause further damage. Hence a cycle of deterioration would be perpetuated.

Alternatively, if damage to the proteoglycan constituent of cartilage were the primary lesion, either by mechanical or enzymatic breakdown, or by the production of abnormal forms, then one would expect that the smaller forms of proteoglycans could escape through the collagen meshwork. Thus a loss of proteoglycan would be seen early in the disease. This alone should not cause a reduction in tensile properties (Kempson et al. 1973), but the loss of material could cause a decrease in thickness although remaining proteoglycans could possibly take up more water. Mechanical damage could perhaps cause the rupture of collagen fibres unsupported to the usual extent by proteoglycan gel, and a deterioration of tensile properties.
We hoped that within the normal group there might be some specimens showing changes similar to those changes found in the osteoarthritic group. Table V shows results from 20 pairs of femoral heads in which both right and left hips were macroscopically normal. The results have been adjusted for age, so that a specimen with exactly the expected value for that age would have a normalised value of 1.00 whilst a higher value than expected for that age is recorded as greater than 1.00. A severely osteoarthritic specimen could be expected to have values less than 1.00 for tensile and compressive properties and proteoglycan content, but greater than 1.00 for swelling. Specimens 2, 3, 8, 9 and 16 (Table V) appear to have "good" cartilage; there was little reduction in mechanical properties, or proteoglycan content, and swelling was less than expected.

In the search for individual specimens which might follow one or other of the above pathways a few can be picked out which support the theory that the initial lesion involves the collagen meshwork as opposed to the proteoglycans. One such is specimen 14R. This shows, particularly at the antero-inferior site, a marked decrease in tensile properties and compressive stiffness, an increase in swelling, but a normal proteoglycan content. Specimens $11 R$ and 17R are similar. Specimens $15 R$ and $4 \mathrm{~L}$ also have marked reduced tensile properties, particularly at the antero-inferior site, and are somewhat softer in compression, but in neither is the proteoglycan content reduced nor the swelling increased. There are others which could be considered as being at an earlier stage in the proposed pathway; for example, $10 \mathrm{~L}$ at the zenith is weaker in tension than expected but normal in compression and proteoglycan content.

Further study of the table shows only three specimens which may support the "proteoglycan first" theory of degeneration. Specimen $4 \mathrm{R}$ at the antero-inferior site has values around normal for all parameters apart from proteoglycan content which is reduced-perhaps the first step towards degenerative cartilage. Specimens $20 \mathrm{~L}$ at the zenith and $1 \mathrm{~L}$, particularly at the antero-inferior site, have a lower proteoglycan content than expected and an increased swelling ability, whilst the remaining properties are fairly normal. Specimen 1L was from a 17-yearold, and immature tissue has been shown previously to contain less proteoglycan than mature tissue (Venn 1978).

The abnormal autopsy group may be representative of early osteoarthritis, as it contained some specimens with definite disease; if so, the results from this group also support the hypothesis that loss of proteoglycan is not the primary event. The group showed significantly greater swelling ability than normal, were softer in compression and weaker in tension at the zenith, but the proteoglycan content was similar to that of the normal autopsy group.

In conclusion, while the results are interesting, they are by no means conclusive. The very small number of 
specimens in the normal autopsy group which showed only a marked loss of proteoglycan, with little or no other changes, suggests that primary loss of proteoglycan is not consistently part of the sequence of pathological changes in early osteoarthritis. Beyond that it was not possible to define a clear pathway for the progression of the disease from the results of the present study. It is suggested that this reflects the heterogeneity of the disease, and that the cause of the disease is multifactorial.

\section{CONCLUSION}

1. A large proportion of abnormal articular cartilage was found in randomly collected autopsy material.

2. The tensile strength of cartilage decreased significantly with increasing age at both locations tested. Other significant changes with age were a decrease in water content at the zenith and of bone density at the antero-inferior site.

3. There was little similarity in the properties of cartilage

Table $\mathbf{V}$. The results of 20 paired femoral heads, normalised for age

\begin{tabular}{|c|c|c|c|c|c|c|c|c|c|c|c|}
\hline & & Antero-i & rior site & & & & Zenith si & & & & \\
\hline & & Tensile s & ngth & & Compres- & & Tensile s & ngth & & Compres- & \\
\hline $\begin{array}{l}\text { Specimen } \\
\text { number }\end{array}$ & $\begin{array}{l}\text { Age } \\
\text { (years) }\end{array}$ & Surface & Mid zone & Swelling & $\begin{array}{l}\text { sive } \\
\text { modulus }\end{array}$ & $\begin{array}{l}\text { Proteo- } \\
\text { glycan }\end{array}$ & Surface & Mid zone & Swelling & $\begin{array}{l}\text { sive } \\
\text { modulus }\end{array}$ & $\begin{array}{l}\text { Proteo- } \\
\text { glycan }\end{array}$ \\
\hline $\begin{array}{l}\text { IL } \\
\text { IR }\end{array}$ & $\begin{array}{l}17 \\
17\end{array}$ & $\begin{array}{l}1.04 \\
1.14\end{array}$ & $\begin{array}{l}1.53 \\
1.25\end{array}$ & $\begin{array}{l}2.70 \\
1.17\end{array}$ & $\begin{array}{l}1.00 \\
0.86\end{array}$ & $\begin{array}{l}0.68 \\
1.22\end{array}$ & $\begin{array}{l}0.65 \\
0.90\end{array}$ & $\begin{array}{l}1.30 \\
0.79\end{array}$ & $\begin{array}{l}1.78 \\
1.12\end{array}$ & $\begin{array}{l}1.25 \\
0.79\end{array}$ & $\begin{array}{l}0.84 \\
0.76\end{array}$ \\
\hline $2 \mathrm{~L}$ & 19 & 0.98 & - & 0.68 & 0.90 & 1.10 & 1.24 & 1.09 & 0.48 & 0.92 & 0.82 \\
\hline $2 \mathrm{R}$ & 19 & 1.30 & 0.74 & 0.20 & 0.73 & 1.01 & 0.95 & 1.34 & 1.17 & 0.93 & 0.94 \\
\hline $3 \mathrm{~L}$ & 29 & - & - & - & 0.90 & 1.16 & 1.28 & 0.83 & - & 1.21 & 1.02 \\
\hline $3 \mathrm{R}$ & 29 & $\ldots$ & - & - & 1.26 & 1.18 & - & - & - & 0.77 & 1.14 \\
\hline $4 \mathrm{~L}$ & 47 & 0.63 & 0.36 & 0.87 & 0.75 & 1.00 & 0.78 & 0.69 & 1.36 & 1.11 & 0.98 \\
\hline $4 R$ & 47 & 0.90 & 1.20 & 1.04 & 1.16 & 0.55 & - & & 0.95 & 1.17 & 1.19 \\
\hline $5 \mathrm{~L}$ & 50 & ..- & $\ldots$ & 0.88 & 0.63 & -_ & 0.52 & 0.47 & - & 1.24 & \\
\hline $5 R$ & 50 & 1.04 & 0.59 & 1.23 & 0.67 & - & 0.72 & 1.01 & 1.06 & 0.47 & \\
\hline $6 \mathrm{~L}$ & 54 & & $\ldots$ & - & 1.34 & 1.03 & 0.98 & - & - & 1.70 & 1.09 \\
\hline $6 \mathrm{R}$ & 54 & - & - & - & 1.63 & 0.99 & - & 0.23 & - & 1.39 & 1.01 \\
\hline $7 \mathrm{~L}$ & 57 & 1.28 & 0.99 & 0.55 & 1.31 & 0.93 & 1.21 & 0.88 & 0.61 & 0.95 & 1.00 \\
\hline $7 \mathrm{R}$ & 57 & 1.01 & 0.60 & 1.16 & 1.11 & 1.14 & 0.71 & 0.74 & 1.55 & 0.56 & 0.74 \\
\hline $8 \mathrm{~L}$ & 62 & 0.98 & 0.78 & 0.54 & 0.97 & 1.01 & 1.29 & 0.77 & 0.50 & 1.16 & 1.00 \\
\hline $8 \mathrm{R}$ & 62 & 1.40 & 0.85 & 0.69 & 1.10 & 1.24 & 1.19 & 0.77 & 0.39 & 0.97 & 0.97 \\
\hline $9 \mathrm{~L}$ & 65 & 0.78 & 1.08 & 0.02 & 1.45 & 1.08 & 1.14 & 1.25 & 0.51 & 0.85 & 1.01 \\
\hline $9 R$ & 65 & 1.21 & 0.90 & 0.15 & 1.02 & 1.00 & 1.88 & 1.86 & 0.43 & 1.23 & 1.01 \\
\hline $10 \mathrm{~L}$ & 67 & 1.03 & - & - & 1.22 & 1.19 & 0.50 & 0.43 & - & 1.12 & 1.02 \\
\hline $10 \mathrm{R}$ & 67 & 1.19 & 0.41 & - & 1.23 & 1.25 & 0.82 & - & - & 0.86 & 0.95 \\
\hline $11 \mathrm{~L}$ & 67 & - & - & 0.98 & 0.61 & - & 0.63 & 0.52 & 1.00 & 1.19 & - \\
\hline $11 R$ & 67 & 0.59 & - & 1.93 & 0.42 & 0.96 & 0.79 & 0.25 & 0.64 & 0.87 & 0.99 \\
\hline $12 \mathrm{~L}$ & 69 & 0.83 & - & - & - & - & 0.74 & 1.21 & 0.50 & 0.88 & 1.09 \\
\hline $12 R$ & 69 & $\begin{array}{l}0.03 \\
-\end{array}$ & - & - & - & - & 1.61 & 1.41 & 0.92 & 1.13 & 0.85 \\
\hline $13 \mathrm{~L}$ & 70 & 1.62 & - & 0.57 & 1.15 & 1.23 & 0.74 & 0.85 & 0.44 & 1.01 & 1.03 \\
\hline $13 R$ & 70 & - & - & 0.99 & 0.36 & 1.23 & 0.96 & 1.08 & 0.67 & 0.95 & 1.04 \\
\hline $14 \mathrm{~L}$ & 71 & 1.17 & 2.48 & 0.46 & 1.11 & 1.02 & 1.04 & 1.46 & 0.32 & 0.77 & 0.93 \\
\hline $14 R$ & 71 & 0.40 & 0.27 & 1.55 & 0.74 & 1.14 & 0.55 & 0.75 & 0.96 & 0.89 & 1.11 \\
\hline $15 \mathrm{~L}$ & 75 & 0.61 & - & 1.15 & 0.84 & 0.62 & 0.80 & -_ & 1.69 & 0.69 & 1.00 \\
\hline ISR & 75 & 0.57 & 0.46 & 0.80 & 0.74 & 1.14 & 1.32 & 0.65 & 0.72 & 0.84 & 0.92 \\
\hline $16 \mathrm{~L}$ & 79 & - & $\ldots$ & 0.59 & 1.19 & 1.18 & 2.20 & 1.14 & 1.28 & 0.86 & 1.01 \\
\hline $16 R$ & 79 & 1.62 & 1.08 & 0.26 & 1.71 & 1.06 & 1.02 & 0.86 & 1.15 & 0.76 & 0.99 \\
\hline $17 \mathrm{~L}$ & 80 & 0.51 & 1.95 & 1.25 & 0.42 & 0.88 & 1.45 & 1.45 & - & - & - \\
\hline $17 \mathrm{R}$ & 80 & 0.58 & - & 1.42 & 0.57 & 1.06 & - & - & 0.70 & 0.70 & 0.97 \\
\hline $18 \mathrm{~L}$ & 81 & 1.37 & 0.81 & 1.61 & 0.41 & 0.96 & - & 1.79 & 0.60 & 0.33 & 1.05 \\
\hline $18 \mathrm{R}$ & 81 & 0.68 & 0.87 & 0.88 & 0.64 & 0.97 & 0.70 & 2.13 & 0.59 & 0.99 & 0.97 \\
\hline 19L & 85 & - & - & - & 1.81 & 0.98 & - & - & - & 1.00 & 0.86 \\
\hline $19 R$ & 85 & 2.06 & 2.31 & - & 1.93 & 0.96 & - & - & - & 1.03 & 0.83 \\
\hline $20 \mathrm{~L}$ & 90 & - & - & 1.92 & 0.50 & 0.98 & 1.49 & - & 3.59 & 1.45 & 0.58 \\
\hline $20 \mathrm{R}$ & 90 & 1.85 & - & 0.77 & 1.51 & 1.01 & 0.51 & - & 1.08 & 1.60 & 0.94 \\
\hline
\end{tabular}


from left and right femoral heads of the same individual.

4. Cartilage from the zenith of the femoral head differed, both mechanically and biochemically, from that of the antero-inferior sector.

5. There was no simple dependency of compressive stiffness, as measured by the two-second creep modulus, on proteoglycan content.

6. Loss of proteoglycan was not the initial event in most specimens showing changes like early osteoarthritis.

The authors wish to acknowledge Dr P. Byers for his help in classifying the autopsy specimens; Dr Helen Beard and Dr M. Marshall for donating the antisera to collagen and proteoglycan, and fibronectin respectively: and $\mathrm{Mr} \mathrm{M}$. Haddaway for assistance with the microfocal radiographs.

\section{REFERENCES}

Ali SY, Bayliss MT. Enzymic changes in human osteoarthrotic cartilage. In: Ali SY. Elves MW, Leaback DH, eds. Normal and osteosarthrotic articular cartilage: Proceedings of the symposium held on 57 November. 1973. London: Institute of Orthopaedics, 1974:189205.

Bader DL, Kempson GE, Barrett AJ, Webb W. The effects of leucocyte elastase on the mechanical properties of adult human articular cartilage in tension. Biochim Biophys Acta 1981:677: 103-8.

Bollet AJ, Nance JL. Biochemical findings in normal and osteoarthritic articular cartilage. II Chondroitin sulfate concentration and chain length, water and ash content. $J$ Clin Invest 1966:45:1170 77.

Byers PD. What is osteoarthritic cartilage? In: Ali SY. Elves MW, Leaback DH. eds. Normal and osteoarthrotic articular cartilage: Proceedings of the symposium held on 5-7 November, 1973. London: Institute of Orthopaedics 1974:131-39.

Byers PD, Contepomi CA, Farkas TA. A post mortem study of the hip joint: including the prevalence of the features of the right side. Ann Rhc'um Dis 1970:29:15 31

Byers PD, Maroudas A, Oztop F, Stockwell RA, Venn MF. Histological and biochemical studies on cartilage from osteoarthrotic femoral heads with special reference to surface characteristics. Connect Tissuc' Res 1977:5:41-9.

Chaminade F, Stanescu V, Stanescu R, Maroteaux P, Peyron JG. Noncollagenous proteins in cartilage of normal subjects and patients with degenerative joint disease: a gel electrophoretic study. Arthritis Rh'um 1982:25:1078 83.

Eyre DR. Collagen cross-linking. In: Akeson WH. Bornstein P. Glimcher MJ. eds. American Academy of Orthopaedic Surgeons: Simposium on heritahle disorders of connective tissue. San Diego, California. May 1980. St Louis: CV Mosby 1982:43 52.

Freeman MAR. The pathogenesis of idiopathic ("primary") osteoarthrosis: an hypothesis. In: Nuki G, ed. The aetiopathogenesis of osteourthrosis. Tunbridge Wells: Pitman Medical, 1980:90 2.

Garg HG, Swann DA. Age-related changes in chemical composition of bovine articular cartilage: the structure of high-density proteoglycans. Biochem J 1981:193:459-68.

Hjertquist SD, Lemperg R. Identification and concentration of the glycosaminoglycans of human articular cartilage in relation to age and osteoarthritis. Calcif Tissue Res 1972:10:223 37.

Hultkrantz W. Ueber die Spaltrichtungen der Gelenkknorpel. Verh Anat Ges (Kiel) 1898:248 56.

Jerring K. Osteoarthritis of the hip: epidemiology and clinical role. Acta Orihop Scand 1980:51:523 30.

Kempson GE. Relationship between the tensile properties of articular cartilage from the human knee and age. Ann Rheum Dis 1982:41: $508-11$.

Kempson GE, Muir H, Swanson SAV, Freeman MAR. Correlations between stiffness and the chemical constituents of cartilage on the human femoral head. Biochim Biophy:s Acta 1970:215:70 7 .

Kempson GE, Freeman MAR. Swanson SAV. The determination of a creep modulus for articular cartilage from indentation tests of the human femoral head. $J$ Biomech 1971a:4:239 50.
Kempson GE, Spivey CJ, Swanson SAV, Freeman MAR. Patterns of cartilage stiffness on normal and degenerate human femoral heads. J Biomech 1971b:4:597-609.

Kempson GE, Muir H, Pollard C, Tuke M. The tensile properties of the cartilage of human femoral condyles related to the content of collagen and glycosaminoglycans. Biochim Biophys Acta 1973:297: 45672 .

Lothe K, Spycher MA, Rüttner JR. Human articular cartilage in relation to age: a morphometric study. Exp Cell Biol 1979:47:22-8.

McDevitt CA, Muir H. Biochemical changes in the cartilage of the knee in experimental and natural osteoarthritis in the dog. J Bone Joint Surg [Br] 1976:58-B:94-101.

Mankin HJ. The pathophysiology of osteoarthritis and implications in epidemiology. In: Peyron JG, ed. Epidemiology of osteoarthritis. Symposium. Paris, June 1980. Paris: Geigy, 1980:30 9

Mankin HJ, Johnson ME, Lippiello L. Biochemical and metabolic abnormalities in articular cartilage from osteoarthritic human hips: III Distribution and metabolism of amino sugar-containing macromolecules. J Bone Joint Surg $[\mathrm{Am}]$ 1981:63 A:1319.

Mankin HJ, Thrasher AZ. Water content and binding in normal and osteoarthritic human cartilage. J Bone Joint Surg $[\mathrm{Am}]$ 1975: 57 A: $76-80$.

Maroudas A. Balance between swelling pressure and collagen tension in normal and degenerate cartilage. Nature 1976;260:8089.

Maroudas A, Thomas H. A simple physicochemical micromethod for determining fixed anionic groups in connective tissue. Biochim Biophys Acta 1970:215:214 6.

Maroudas A, Venn M. Chemical composition and swelling of normal and osteoarthrotic femoral head cartilage: II Swelling. Ann Rheum Dis 1977:36:399 406 .

Meachim G. Light microscopy of Indian ink preparations of fibrillated cartilage. Ann Rheum Dis 1972:31:457 64.

Meachim G, Emery IH. Cartilage fibrillation in shoulder and hip joints in Liverpool necropsies. J Anat 1973:116:161-79.

Park WM, Haddaway MJ, Roberts PJ, Roberts S, McCall IW. Nonvascular digital imaging. Digital radiology: physical and clinical aspects. Proceedings of a meeting held on 9 March 1983. London: Institute of Physical Sciences in Medicine, 1984:123 36.

Parker RE. Continuous distributions: tests of significance. In: Introductory statistics for hiology. 2nd ed. London: Arnold, 1979:18 25.

Pauwels F. Physiological stress at the upper end of the femur. Biomechanics of the normal and diseased hip: theoretical foundation. technique and results of treatment: an atlas. Berlin etc: SpringerVerlag 1976:17.

Radin EL, Swann DA, Paul IL, McGrath PJ. Factors influencing articular cartilage wear in vitro. Arthritis Rheum 1982:25:974 80 .

Roberts S. Alterations in the articular cartilage of the femoral head in osteoarthritis. University of Birmingham: $\mathrm{PhD}$ thesis 1984:84-94.

Roth V, Mow VC. The intrinsic tensile behavior of the matrix of bovine articular cartilage and its variation with age. J Bone Joint Surg [Am] 1980;62-A:1102-17

Schnider SL, Kohn RR. Effects of age and diabetes mellitus on the solubility of collagen from human skin, tracheal cartilage and dura mater. Exp Gerontol 1982:17:185 94.

Scott JE, Dorling J. Differential staining of acid glycosaminoglycans (mucopolysaccharides) by alcian blue in salt solutions. Histochenie 1965:5:221 33 .

Sweet MB, Thonar EJ, Immelman AR, Solomon L. Biochemical changes in progressive osteoarthrosis. Ann Rheum Dis 1977:36: 38798.

Trotter M, Broman GE, Peterson RR. Densities of bones of white and negro skeletons. J Bone Joint Surg $[\mathrm{Am}]$ 1960;42 A:50 8.

Vasan N. Proteoglycans in normal and severely osteoarthritic human cartilage. Biochem J 1980;187:781-7.

Venn MF. Variation of chemical composition with age in human femoral head cartilage. Ann Rheum Dis 1978:37:168-74.

Venn M, Maroudas A. Chemical composition and swelling of normal and osteoarthrotic femoral head cartilage: I Chemical composition. Ann Rheum Dis 1977:36:121 9.

Weightman B, Kempson GE. Load carriage. In: Freeman MAR, ed. Adult articular cartilage. 2nd ed. London: Pitman Medical, 1979: 291-331.

Wirth CR, Augello FA, Mow VC, Roth V. Variation of tensile properties of human patellar cartilage with age and histological indices. Orthop Trans 1980:4:177-8. 